\title{
INTERPERSONAL PROBLEMS AND INTERPERSONAL EXPECTATIONS IN EVERYDAY LIFE
}

\author{
KENNETH D. LOCKE \\ University of Idaho
}

\begin{abstract}
Are interpersonal problems related to interpersonal expectations? To answer this question, 150 undergraduates reported problems with being too agentic, unagentic, communal, or uncommunal. Then, over one week, each time they imagined how someone might react to them, they recorded who the other person was, how the person reacted, their feelings, and any imagined counter-reactions. Whereas uncommunal people imagined others not caring and themselves not disclosing, agentic people imagined others criticizing and themselves arguing. Agentic and uncommunal people also expected unresponsive and unsupportive reactions. Unagentic people did not expect more negative reactions, but did expect being unable to listen or speak openly when negative reactions or feelings did occur. Imagined reactions generally tended to evoke feelings of anger in agentic people, insecurity in unagentic people, shame in communal people, and disconnection in uncommunal people. Thus, changing everyday interpersonal expectations may help reduce chronic interpersonal problems.
\end{abstract}

Interpersonal problems are recurrent difficulties in relating to others, and are a common reason why people seek psychotherapy (Horowitz, Rosenberg, \& Bartholomew, 1993). The interpersonal circumplex provides a general model for organizing and assessing interpersonal dispositions, including interpersonal problems (Gurtman, 1992). The model maps interpersonal stances onto two dimensions: agency and communion (Horowitz, 2004). Figure 1 shows that these two orthogonal dimensions together define an "interpersonal circle" (Kiesler, 1983) that can be subdivided into eight octants. Analyses of clinical intake interviews

\footnotetext{
I am grateful to Tom Sneed for his help in collecting and entering the data.

Data from this study was presented at the 2001 annual meeting of the Society for Interpersonal Theory and Research.

Correspondence concerning this article should be addressed to Kenneth Locke, Department of Psychology, University of Idaho, Moscow, ID 83844. E-mail: klocke@uidaho.edu.
} 
shows that people complain of interpersonal problems associated with all regions of the interpersonal circle (Alden, Wiggins, \& Pincus, 1990).

The most common self-report measure of problems associated with each octant of the interpersonal space is the Inventory of Interpersonal Problems (IIP; Horowitz, Alden, Wiggins, \& Pincus, 2000). Figure 1 shows the names (and two-letter codes) for the eight IIP octant scales. The following are examples of IIP items from each octant (moving counterclockwise from the top of the circle): "I try to control other people too much" (agentic), "I fight with other people too much" (agentic and uncommunal), "It is hard for me to show affection to people" (uncommunal), "I am too afraid of other people" (unagentic and uncommunal), "It is hard for me to be assertive with another person (unagentic), "I am too gullible" (unagentic and communal), "I try to please other people too much" (communal), "I tell personal things to other people too much" (agentic and communal). Individual differences in these types of interpersonal problems have been shown to predict individual differences in such variables as personality disorder symptoms (e.g., Matano \& Locke, 1995; Pincus \& Wiggins, 1990; Soldz, Budman, Demby, \& Merry, 1993) and psychotherapy processes and outcomes (e.g., Gurtman, 1996; Horowitz et al., 1993; Muran, Segal, Samstag, \& Crawford, 1994).

A social cognitive approach to understanding interpersonal problems assumes that people who react differently to social situations think differently about those situations. Of particular importance may be interpersonal expectations - expectations about how others will react to the self and how the self will respond to those reactions. When a person imagines the reaction of another person, the imagined reaction is probably a reflection of expectations specific to the particular situation and relationship as well as more general interpersonal scripts and schemas (Andersen \& Chen, 2002; Baldwin, 1992). For example, if Ben is considering asking a favor of Sue, the reaction Ben expects may depend on the particular favor being asked, past experiences with Sue and other people reminiscent of Sue, and implicit schemas concerning how people generally respond to such requests. To the extent that different people have different schemas and those schemas shape momentary expectations, different people will tend to have reliably different expectations. These individual differences in interpersonal expectations may explain some of the individual differences in interpersonal problems (Pierce \& Lydon, 1998). To the extent that they do, changing chronic, maladaptive interpersonal expectations may help people to overcome chronic, maladaptive interpersonal patterns.

The purpose of the current study was to test if there was in fact a relationship between interpersonal expectations and interpersonal problems. There are several ways in which interpersonal problems and interpersonal expectations might be related. First, interpersonal problems 


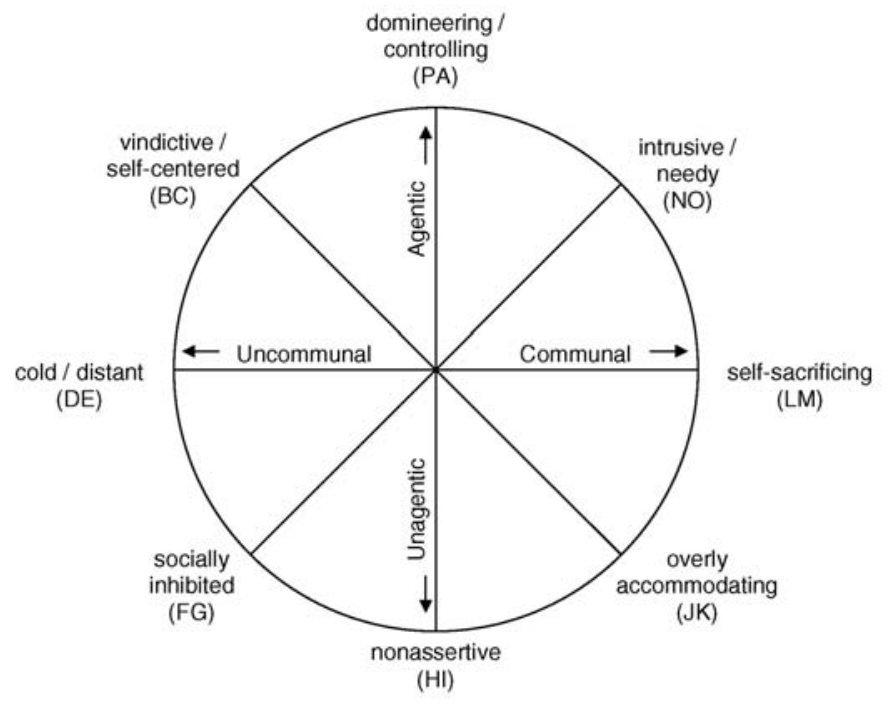

FIGURE 1. The interpersonal circumplex (with the IIP scale name for each octant).

may be related to expectations for how others will act. For example, problems with being too uncommunal might emerge in people who expect others to act cold and rejecting (i.e., uncommunal) toward them and so defensively and preemptively act cold and rejecting toward others. Second, interpersonal problems may be related to how sensitive or insensitive people are to the reactions of others. For example, problems with being too avoidant might emerge in people who (even if they do not expect to receive more negative reactions than others do) expect to be more stung by the negative reactions they do receive. Finally, interpersonal problems may be related to expectations for the self. For example, people who have developed chronic problems with being too uncommunal are likely to anticipate themselves being uncommunal in future interpersonal encounters.

To assess spontaneous, naturalistic, imagined reactions, the study employed an event-contingent self-recording procedure (Wheeler \& Reis, 1991). During a seven-day period, each time participants noticed themselves anticipating how another person might react to them, they com- 
pleted an "Imagined Reaction Record" (IRR). ${ }^{1}$ The IRR assessed who was the imagined other and how they reacted, as well as any imagined counter-reactions and feelings that the imagined reaction evoked. The IRR specifically assessed one reaction and one counter-reaction from each quadrant of the interpersonal circumplex. The participants also completed the IIP. Thus, the study was designed to examine the nature and impact of brief imagined reactions that occur in the course of everyday life, and whether the nature and impact of those everyday imagined reactions were associated with more enduring interpersonal problems.

\section{METHOD}

\section{Participants}

The participants were 150 undergraduates (103 female, 47 male, age $M=$ 20.4 years, $S D=4.3$ ), who participated for course credit in various psychology classes.

\section{MATERIALS}

IIP. The IIP is a 64-item self-report measure that assesses problems associated with each octant of the interpersonal circumplex (Horowitz et al., 2000). Respondents rate how distressed they have been by each problem on a 0 (not at all) to 4 (extremely) scale. The IIP scales have adequate internal consistency, test-retest reliability, a circumplex structure, convergent validity with circumplex measures of interpersonal traits (Interpersonal Adjective Scales; Wiggins, Trapnell, \& Phillips, 1988) and interpersonal motives (Circumplex Scales of Interpersonal Values; Locke, 2000), and predictive utility in clinical settings (Horowitz et al., 2000). In the current sample, the mean scores and Cronbach's alpha for each scale were: PA $(M=0.83, S D=0.51, \alpha=.67), \mathrm{BC}(M=0.91, S D=0.53, \alpha=.68)$,

1. The imagined reactions studied in this article should not be confused with the "imagined interactions" studied in the communication literature (Honeycutt \& Ford, 2001). An imagined reaction is a conscious representation of how another person might react to the self. Imagined interactions are internal conversations with others who are not physically present. Imagined reactions differ from imagined interactions in five ways. First, imagined reactions often occur with the other person present. Second, imagined reactions may be nonverbal or not expressed (e.g., "He will smile," "She will feel disappointed"). Third, imagined reactions may be reactions to physical features or possessions (e.g., a new haircut), unintentional actions (e.g., spilling a drink), or actions not directed at the imagined audience (e.g., something one did to a third party). Fourth, imagined reactions can occur without imagining any counter-reaction from the self. Fifth, imagined reactions are expectations about the future, whereas imagined interactions often involve reviewing and rewriting past conversations (Honeycutt \& Ford, 2001). 
$\mathrm{DE}(M=0.86, S D=0.62, \alpha=.77), \mathrm{FG}(M=1.25, S D=0.80, \alpha=.87), \mathrm{HI}(M$ $=1.39, S D=0.69, \alpha=.81)$, JK $(M=1.41, S D=0.70, \alpha=.78), \operatorname{LM}(M=1.47$, $S D=0.69, \alpha=.77), \mathrm{NO}(M=0.98, S D=0.56, \alpha=.66)$. Measures of problems associated with the four cardinal vectors of the circumplex (agentic, unagentic, communal, and uncommunal) were computed as follows: Vector Score $=\sigma S_{i} \cos \theta_{i}$, where the $S_{i}$ are the scores for the three octants loading positively on the direction being measured and the $\theta_{i}$ are the angular discrepancies of those octants from the vector direction. For example, the agentic vector score $=S_{P A} \cos \theta_{P A}+S_{B C} \cos \theta_{B C}+S_{N O C O S} \theta_{N O}=$ $S_{P A}+S_{B C}(.707)+S_{N O}(.707)$. (For further explanation of the mathematics of circumplex scales, see the appendix of Horowitz [2004]).

Imagined Reaction Record (IRR). Each IRR asked participants to record the following information. First, the IRR asked participants to indicate whose reaction they imagined by checking one of the following categories: acquaintance, friend, relative, romantic partner, teacher, stranger, or other. If they marked "other," they were asked to "please specify."

The remaining questions were answered on 0 (not at all) to 4 (definitely) ratings scales and were organized into three sections. The heading of the first section stated: "The other person's reaction was to. .." Under this heading were four items, one from each quadrant of the interpersonal space: ". . invite me to join in an open, two-way dialogue" (communal and agentic), ". . express unconditional love and support" (communal and unagentic), ". . .criticize and attack me" (uncommunal and agentic), and ". . .never really listen or respond to what I was saying or doing" (uncommunal and unagentic). I called these four types of reactions: inviting, supportive, critical, and dismissive.

The heading of the second section stated: "While imagining their reaction, I generally felt. . ." Under this heading were eight feeling words. Subjecting them to a principal components analysis revealed two factors (explaining 54\% and 13\% of the variance, respectively) that roughly correspond to the commonly extracted factors of evaluation and potency (Osgood, Suci, \& Tannebaum, 1957). On the positive end of the "evaluation" factor were the words confident, connected, relaxed, and supported (loadings $=+.74-+.82)$; on the negative end were alienated, angry, ashamed, and insecure (loadings $=-.63--.72$ ). On the high-potency pole of factor two were confident, relaxed, alienated, and angry (loading $=+.09-$ -.27); on the low potency end were ashamed, insecure, supported, and connected (loadings $=+.30-+.61$ ). The eight items were aggregated into four scales based on whether they were high or low on each of the factors. The positive/potent scale (i.e., confident + relaxed) was called confidence ( $\alpha$ $=.76)$; the negative/potent scale (angry + alienated) was called anger ( $\alpha$ $=.70)$; the positive/nonpotent scale (connected + supported) was called 
connection ( $\alpha=.82)$; the negative/nonpotent scale (ashamed + insecure) was called shame $(\alpha=.75)$.

Participants were told to complete the third section only if they imagined themselves reacting to the imagined reaction. This section was completed on $84 \%$ of IRRs. The section heading stated: "My reaction was. .." Under this heading were four items, one from each quadrant of the interpersonal space: “. . .opening up and expressing myself in a clear and honest way" (communal and agentic), ". . .listening and learning a lot from their reactions" (communal and unagentic), ". . . arguing with them" (uncommunal and agentic), and ". . ignoring their reactions" (uncommunal and unagentic). I called these four types of imagined counter-reactions: expressing, listening, arguing, and ignoring.

\section{PROCEDURE}

In small groups, we administered the IIP and then distributed the packet of 15 IRRs along with detailed instructions. The instructions stated: "We often imagine how others will react to us-to what we say and do, and to our appearance and possessions. For example, you might imagine how your parents will react to your switching majors. . .or how your professor will react to your request for a makeup exam. . Each time you notice yourself imagining how another person or group of people might react to you, fill out one of the attached 'Imagined Reaction Record' sheets..." The participants were told to return the packet in one week regardless of the number of record sheets completed.

After seven days, participants who had not returned their packets were reminded to do so either by phone or by e-mail. Ninety-one percent of the participants (97 females, 39 males, mean age $=20.6, S D=4.5$ ) returned their IRRs within ten days. Only these participants were included in the following analyses. The number of IRRs completed ranged from two to $15(M=7.49, S D=4.41$, total number of records $=1,034)$. The number of completed IRRs was unrelated to any other variable.

\section{RESULTS}

The data were imagined reaction records (level-1) nested within participants (level-2). Therefore, the data were analyzed using multilevel random coefficient modeling (Kenny, Kashy \& Bolger, 1998; Nezlek, 2001) following the basic steps outlined in Bryk and Raudenbush (1992). First, for each level-1 variable (reactions, feelings, and counter-reactions), I estimated the intercept for each participant and the between-subjects variation in intercepts. Second, I modeled the between-subjects variance in those level- 1 intercepts as a function of the level- 2 predictors 
(the four IIP vector scores). Third, I estimated the relationships between the level-1 variables. Fourth, I modeled the level-2 variance in those level-1 relationships as a function of the level-2 predictors.

\section{BASIC CHARACTERISTICS OF IMAGINED REACTIONS}

The audiences whose reactions were imagined included (from most to least common) friends $(25.4 \%)$, relatives $(19.5 \%)$, romantic partners $(14.8 \%)$, teachers $(11.6 \%)$, acquaintances $(9.4 \%)$, and strangers $(8.3 \%)$. The remaining $10.9 \%$ of the audiences were marked "other" or were missing. When participants specified the audiences that were marked "other," they were typically persons in professional roles (e.g., policeman, doctor) or former romantic partners. Categorizing friends, relatives, and partners as close others, and acquaintances, teachers, and strangers as not close, $59.7 \%$ were close and $29.3 \%$ were not. Thus, consistent with surveys of imagined interactions (Honeycutt \& Ford, 2001), people reported anticipating the reactions of close others about twice as often as the reactions of distant others.

The mean values of the other IRR variables (imagined reactions, counter-reactions, and affect) were estimated using an unconditional multilevel model with no predictor variables. The level-1 (within-subject) model was:

$$
Y_{i j}=\beta_{0 j}+r_{i j} .(1)
$$

For example, if the outcome is feelings of shame, $Y_{i j}$ is the shame reported on ith IRR by participant $j, b_{0 j}$ is $j$ 's mean shame across all IRRs, and $r_{\mathrm{ij}}$ is a residual component of shame for record $i$. The level-2 (between-subjects) model was:

$$
\beta_{0 j}=\gamma_{00}+u_{0 j}(2)
$$

Continuing the preceding example, $\beta_{0 j}$ is participant $j$ 's mean shame, $\gamma_{00}$ is the shame grand mean, and $u_{0 j}$ is the residual component of shame for $j$.

Table 1 shows the results. People tended to report more positive than negative reactions, counter-reactions, and feelings, $p s<.05$. Thus, the most commonly reported reactions, counter-reactions, and feelings were inviting, expressing, and feeling connected; the least common were dismissing, ignoring, and feeling angry. The last column of Table 1 shows the proportion of level-2 variance (or intraclass correlation) for each variable, which was computed as the between-subjects variance (variance in $u_{0 j}$ ) divided by the total variance. The level-2 variance was less for ratings of reactions than for ratings of counter-reactions, which is sensible given that the source of the anticipated reactions varied, whereas the source of the counter-reactions was always the self. Re- 
TABLE 1. Mean Ratings and Intraclass Correlations for Level-1 Variables

\begin{tabular}{lccc}
\hline & $\gamma_{00}$ & $S E$ & $r_{\text {intraclass }}$ \\
\hline Imagined reaction & & & \\
Critical & 1.38 & 0.07 & 0.13 \\
Dismissive & 0.97 & 0.06 & 0.13 \\
Inviting & 2.06 & 0.07 & 0.14 \\
Supportive & 1.56 & 0.07 & 0.11 \\
Feeling & & & \\
Anger & 1.21 & 0.05 & 0.11 \\
Shame & 1.37 & 0.07 & 0.25 \\
Confidence & 1.62 & 0.06 & 0.17 \\
Connection & 1.69 & 0.06 & 0.13 \\
Counter-reaction & & & \\
Argue & 1.34 & 0.07 & 0.23 \\
Ignore & 0.91 & 0.06 & 0.23 \\
Express & 2.72 & 0.07 & 0.27 \\
Listen & 2.21 & 0.07 & 0.29 \\
\hline
\end{tabular}

Note. All ratings were made on 0 to 4 scales.

gardless, there was significant level-2 variance in all level-1 variables $(p s<.0001)$. So, for all outcomes I tested the effects of both level-1 and level-2 predictors. In the analyses below, the variables were $z$-scored and, in addition, the level-1 predictors were centered within subjects.

\section{EFFECTS OF INTERPERSONAL PROBLEMS}

To model the between-subjects variation in the IRR variables in terms of the between-subjects predictor variables (IIP scores), Equation 2 was expanded as follows:

$$
\beta_{0 j}=\gamma_{00}+\gamma_{01} I I P_{j}+u_{0 j},(3)
$$

where $\mathrm{IIP}_{\mathrm{j}}$ is participant $j$ 's score for a particular IIP vector and $\gamma_{01}$ is the effect of that score. Table 2 shows the results. Agentic problems predicted anticipating others being critical or dismissive (and marginally less supportive) and the self feeling angry and responding with more ignoring (and marginally more arguing). Uncommunal problems predicted anticipating others being less inviting and supportive (and marginally more dismissive) and the self feeling disconnected and responding with more ignoring (and marginally less self-expression). Unagentic problems predicted the self feeling less confident (and marginally less connected) and responding with less self-expression. Communal problems predicted anticipating others being dismissive (but also marginally more supportive) and the self feeling ashamed. 
TABLE 2. Effects of Interpersonal Problems on Imagined Reactions[comma here] Counter-Reactions[comma here] and Feelings

\begin{tabular}{|c|c|c|c|c|c|c|c|c|}
\hline & \multicolumn{8}{|c|}{ Type of Interpersonal Problem } \\
\hline & \multicolumn{2}{|c|}{ Agentic } & \multicolumn{2}{|c|}{ Uncommunal } & \multicolumn{2}{|c|}{ Unagentic } & \multicolumn{2}{|c|}{ Communal } \\
\hline & $\gamma$ & $S E$ & $\gamma$ & $S E$ & $\gamma$ & $S E$ & $\gamma$ & $S E$ \\
\hline \multicolumn{9}{|c|}{ Imagined Reaction } \\
\hline Critical & $0.170^{* *}$ & 0.043 & 0.037 & 0.045 & -0.021 & 0.045 & 0.042 & 0.044 \\
\hline Dismissive & $0.142^{* *}$ & 0.043 & $0.072+$ & 0.044 & 0.024 & 0.044 & $0.088^{*}$ & 0.042 \\
\hline Inviting & -0.022 & 0.046 & $-0.089^{*}$ & 0.044 & -0.059 & 0.045 & 0.036 & 0.044 \\
\hline Supportive & $-0.077+$ & 0.043 & $-0.124^{* *}$ & 0.042 & -0.036 & 0.043 & $0.074 \dagger$ & 0.041 \\
\hline \multicolumn{9}{|l|}{ Feeling } \\
\hline Anger & $0.117^{* *}$ & 0.043 & 0.055 & 0.043 & 0.020 & 0.043 & 0.062 & 0.042 \\
\hline Shame & 0.071 & 0.053 & -0.011 & 0.053 & 0.071 & 0.052 & $0.132^{*}$ & 0.051 \\
\hline Confidence & 0.012 & 0.048 & -0.059 & 0.047 & $-0.106^{*}$ & 0.047 & -0.005 & 0.047 \\
\hline Connection & 0.011 & 0.046 & $-0.090^{*}$ & 0.045 & $-0.078+$ & 0.045 & 0.046 & 0.044 \\
\hline \multicolumn{9}{|c|}{ Counter-reaction } \\
\hline Argue & $0.083+$ & 0.048 & 0.009 & 0.048 & -0.052 & 0.048 & 0.016 & 0.046 \\
\hline Ignore & $0.096^{*}$ & 0.047 & $0.097^{*}$ & 0.047 & 0.045 & 0.047 & 0.043 & 0.046 \\
\hline Express & 0.062 & 0.051 & $-0.096+$ & 0.051 & $-0.102^{*}$ & 0.052 & 0.070 & 0.050 \\
\hline Listen & 0.050 & 0.052 & -0.024 & 0.052 & 0.009 & 0.053 & 0.066 & 0.051 \\
\hline
\end{tabular}

$+p<.1 ;{ }^{*} p<.05 ;{ }^{* *} p<.01$.

\section{EFFECTS OF IMAGINED REACTIONS AND FEELINGS}

The preceding section tested the effects of between-subjects predictors. The following section tested the effects of within-subjects predictors. To do so, Equation 1 was expanded as follows:

$$
Y_{i j}=\beta_{0 j}+\beta_{1 j} X_{i j}+r_{i j}(4)
$$

where $X_{\mathrm{ij}}$ is the predictor and $\beta_{1 \mathrm{j}}$ is the predictor-outcome slope. For example, if $Y$ is confidence and $X$ is anticipated support, $X_{i j}$ is the anticipated support on participant $j$ 's $i$ th IRR, and $\beta_{1 j}$ is $j$ 's support-confidence slope. The following equation was also added to level 2 :

$$
\beta_{1 j}=\gamma_{10}+u_{1 j},(5)
$$

where $\gamma_{10}$ is the mean $\beta_{1 \mathrm{j}}$ across participants and $u_{1 \mathrm{j}}$ is the component of the slope unique to $j$.

Table 3 shows the effects of imagined reactions on affect and counter-reactions; all of the effects were significant and robust. Imagining critical or dismissive reactions predicted negative affect (especially feeling angry and unconnected) and negative counter-reactions (especially arguing). Conversely, imagining inviting and supportive reactions predicted positive affect (especially feeling connected) and positive counter-reactions (both listening and expressing). I also tested the effect of af- 
TABLE 3. Effects of Imagined Reactions on Feelings and Counter-Reactions

\begin{tabular}{|c|c|c|c|c|c|c|c|c|}
\hline & \multicolumn{8}{|c|}{ Imagined Reaction } \\
\hline & \multicolumn{2}{|c|}{ Critical } & \multicolumn{2}{|c|}{ Dismissive } & \multicolumn{2}{|c|}{ Inviting } & \multicolumn{2}{|c|}{ Supportive } \\
\hline & $\gamma$ & $S E$ & $\gamma$ & $S E$ & $\gamma$ & $S E$ & $\gamma$ & $S E$ \\
\hline \multicolumn{9}{|l|}{ Feeling } \\
\hline Anger & 0.626 & 0.033 & 0.562 & 0.038 & -0.442 & 0.040 & -0.387 & 0.034 \\
\hline Shame & 0.347 & 0.038 & 0.206 & 0.037 & -0.243 & 0.037 & -0.249 & 0.037 \\
\hline Confidence & -0.415 & 0.040 & -0.258 & 0.040 & 0.381 & 0.042 & 0.403 & 0.040 \\
\hline Connection & -0.550 & 0.038 & -0.413 & 0.040 & 0.519 & 0.039 & 0.602 & 0.034 \\
\hline \multicolumn{9}{|c|}{ Counter-reaction } \\
\hline Argue & 0.552 & 0.039 & 0.402 & 0.048 & -0.304 & 0.042 & -0.234 & 0.044 \\
\hline Ignore & 0.318 & 0.040 & 0.365 & 0.047 & -0.257 & 0.039 & -0.232 & 0.039 \\
\hline Express & -0.232 & 0.038 & -0.206 & 0.044 & 0.365 & 0.037 & 0.327 & 0.036 \\
\hline Listen & -0.289 & 0.041 & -0.263 & 0.038 & 0.367 & 0.037 & 0.242 & 0.042 \\
\hline
\end{tabular}

Note. All effects were significant[comma here] $p s<.001$.

fect on counter-reactions. As expected, positive affects predicted more positive and less negative counter-reactions, while the reverse was true for the negative affects. All of the effects were significant ( $p s<.001)$ with the exception that shame did not significantly predict listening or ignoring.

\section{MODERATING EFFECTS OF INTERPERSONAL PROBLEMS}

Finally, I tested if the level-2 predictors could predict the level-1 slopes modeled in the preceding section. To do so, Equation 5 was expanded as follows:

$$
\beta_{1 \mathrm{j}}=\gamma_{10}+\gamma_{11} \mathrm{IIPj}+u_{1 \mathrm{j},}(6)
$$

where $\gamma_{11}$ is the effect of the IIP scale. Given the number of tests, only effects significant at $p<.01$ are reported. Uncommunal problems predicted greater negative impacts of anger on listening $\left(\gamma_{11}=-.120, S E=\right.$ $.037)$ and self-expression $(\gamma=-.097, S E=.035)$ and of shame on listening $(\gamma=-.105, S E=.041)$. Unagentic problems predicted greater positive impacts of connected feelings on listening $(\gamma=.096, S E=.036)$ and not arguing $(\gamma=-.104, S E=.034)$; and greater negative impacts of critical reactions on listening $(\gamma=-.111, S E=.040)$, dismissive reactions on self-expression $(\gamma=-.145, S E=.041)$, and anger on self-expression $(\gamma=$ $-.092, S E=.035)$. Agentic and communal problems did not moderate any level-1 slopes. 


\section{DISCUSSION}

Records of everyday interpersonal expectations showed that people were more likely to expect positive (supportive and inviting) than negative (critical or dismissive) reactions from others, were more likely to expect positive (listening and opening up) than negative (arguing or ignoring) counter-reactions from the self, and were more likely to experience positive (confident and connected) than negative (angry and ashamed) feelings. Not surprisingly, anticipating positive reactions evoked positive feelings and counter-reactions, whereas anticipating negative reactions evoked negative feelings and counter-reactions. However, there was variance in these findings across individuals and some of that variance was related to interpersonal problems.

Consider first the effects of interpersonal problems on the relationships among imagined reactions, feelings, and counter-reactions. The imagined counter-reactions of unagentic individuals seemed especially sensitive to their feelings and others' anticipated reactions. Specifically, unagentic problems predicted stronger effects of connection on listening and not arguing, of anger and dismissive reactions on not expressing, and of critical reactions on not listening. Uncommunal problems similarly predicted stronger effects of anger and shame on not listening, and of anger on not expressing. Thus, the general pattern was for people whose problems involve either avoiding communion or avoiding agency to expect themselves to close down - to avoid listening openly or avoid expressing themselves openly-when experiencing either negative reactions or negative feelings. These findings suggest that sensitivity to punishment-a robust individual difference variable that influences a broad range of outcomes (e.g., Gable, Reis, \& Elliot, 2000; Gray, 1987; Higgins, 1998) - may play a role in the etiology of interpersonal problems involving withdrawal from communion or agency.

Interpersonal problems also had direct effects on the types of reactions and counter-reactions expected and feelings experienced. In terms of feelings, being too agentic predicted more anger, being too unagentic predicted less confidence, being too communal predicted more shame, and being too uncommunal predicted less connection. Two general patterns are evident. First, interpersonal problems-regardless of the type-predicted worse affect. Second, whereas too much agency or communion predicted too much of the negative feelings of anger or shame, not enough agency or communion predicted not enough of the positive feelings of confidence or connection.

In terms of counter-reactions, overly agentic or uncommunal people were particularly likely to imagine themselves ignoring others, and overly uncommunal and unagentic people were particularly likely to 
imagine themselves not being open with others. These links make sense, but, then again, it is not surprising that how people describe themselves reacting across many situations (on the IIP) predicts how they expect themselves to react in a particular situation (on the IRR). Instead, the more striking findings are those showing links between individuals' interpersonal problems and their expectations concerning how others will react to the self. For example, people who expected others to provide neither attention nor love tended to report problems with being too uncommunal, while people who expected others to be critical tended to report problems with being too agentic. These findings suggest that overly domineering or overly cold behaviors may be self-protective. By assuming an aloof stance, uncommunal people (who expect others to treat them as unworthy of love) affirm their disinterest in others' love. By asserting their superiority, agentic people (who expect others to treat them as unworthy of respect) affirm their invulnerability to others' criticism.

Interestingly, imagining dismissive reactions predicted not only agentic problems but also communal problems, suggesting that very agentic and very communal behaviors may both be ways to prevent others from ignoring the self. The difference is that the overly agentic people also expected unsupportive or critical reactions, whereas the overly communal people also expected supportive reactions. Another apparently contradictory pair of findings was that anticipating unsupportive reactions weakly predicted being too agentic as well as being too unagentic; these findings can be reconciled by considering that people who expect others to be unsupportive can respond by either pushing harder (appearing, in IIP terms, "domineering") or giving up (appearing "nonassertive").

The preceding explanations of the correspondence between imagined reactions and interpersonal problems assume that the expectations are causing the problems, but the reverse- that the problems are causing the expectations-may also be true. For example, domineering persons may elicit criticism from others and so come to (accurately) expect critical reactions, and cold persons may elicit coldness from others and so come to (accurately) expect cold reactions. A third possibility is that implicit interpersonal scripts or relationship schemas (Baldwin, 1992) may be responsible for both the imagined reactions and the interpersonal problems. People whose scripts portray power struggles may tend to expect and enact power struggles, and people whose scripts portray distance may tend to expect and enact distance. Of course, all of these effects may occur, creating positive feedback loops or "self-fulfilling prophecies." For example, an underlying schema of competition may facilitate imagining threats that may lead to domineering behaviors that 
are then challenged, thus reinforcing the original schema. An underlying schema of disconnection may facilitate imagining being unloved, which may lead to aloof behaviors that push others away, thus entrenching the preexisting schema.

On the other hand, research suggests that explicit and implicit representations may play distinct roles in regulating behavior. For example, research suggests that explicit or self-attributed motives (assessed by self-report measures) regulate behaviors that are explicitly linked to those motives and are being regulated consciously, while implicit motives (assessed by projective measures) regulate behaviors that are not being consciously regulated and for which the behavior-motive link is automatic or intrinsic to enacting the behavior (Bornstein, 1998; McClelland, Koestner, \& Weinberger, 1989). Similarly, there is evidence that explicit attitudes (assessed by self-report) regulate behaviors that are explicitly linked to the attitude and are being regulated consciously, while implicit attitudes (assessed by reaction time) can regulate behaviors that are not being consciously regulated or are not explicitly linked to the attitude (Asendorpf, Banse, \& Muecke, 2002; Dovidio, Kawakami, \& Gaertner, 2002; see Wilson, Lindsey, \& Schooler, 2000 for a review). Using the same logic, explicit (consciously imagined) audiences may influence behaviors that are being regulated consciously and to which those audiences might at some point react, while implicit (unconsciously primed) audiences (e.g., Baldwin \& Holmes, 1987; Fitzsimons \& Bargh, 2003) may influence behaviors that are not being consciously regulated and that the audiences may never observe. A related question for future research is whether interpersonal problems have the same relationships with unconscious expectations as they do with conscious expectations - for example, do unagentic people, who in the current study reacted more strongly to negative interpersonal expectations, also react more strongly to negative interpersonal primes?

If imagined reactions do influence interpersonal problems, imagined reactions may be a useful target of interventions for treating interpersonal problems. Indeed, imagined reactions are just the interpersonal analogs of automatic thoughts, a key target of cognitive therapies (Beck, 1976). Just as people can benefit from monitoring and changing their automatic thoughts, people may also benefit from monitoring and changing their automatic imagined reactions. In fact, cognitive-behavioral therapies make use of event-contingent self-recording forms-often called self-monitoring assignments-similar to the IRRs used in this study (for details, see Cone [1999] and the other articles in the special issue of Psychological Assessment on self-monitoring). Thus, one way intervention studies could manipulate interpersonal expectancies would be to use diaries that are similar to those used in the current study, but that 
ask participants to either monitor or deliberately imagine only certain types of reactions - presumably, more positive or more realistic ones. As noted above, imagined reactions and interpersonal problems may in turn be linked with actual reactions from others and implicit interpersonal schemas in a self-sustaining cycle; however, imagined reactions would seem a more accessible target for therapeutic interventions than either implicit schemas (which people are not aware of directly) or actual reactions from people other than the therapist.

\section{LIMITATIONS AND CONCLUSIONS}

As a method of gathering data, event-contingent diaries have both strengths and limitations (Reis \& Gable, 2000; Wood, 1996). On the one hand, they open a window on specific types of experiences as they occur in natural settings; on the other hand, they only reveal those experiences that participants notice and record. For example, in the current study, participants reported an average of 7.5 imagined reactions over the course of a week-surely less than the number of actual occurrences. The key question, therefore, is whether the sample of recorded experiences is representative of the population of naturalistic experiences; and, as yet, there are no published data addressing this question.

A second limitation is that record sheets can only ask a limited number of questions without burdening or confusing the participants. Thus, the current study's IRR assessed only a subset of the types of reactions, counter-reactions, and feelings that could be assessed. A related limitation is that while interpersonal interactions are an "unbroken causal loop" in which the responses of each person are both a cause and an effect of the responses of the other (Carson, 1969), the current study only assessed expectations for one part of the "interpersonal transaction cycle" (Wagner, Kiesler, \& Schmidt, 1995)—namely, the effect of others' reactions on the self's feelings and counter-reactions. Consider, for example, a perplexing finding from the current study: overly communal behaviors were related both to images of others being dismissive and images of others being supportive. One explanation is that what compels overly communal people are fears of being dismissed and fantasies of being embraced (as the current study suggests) combined with expectations that they will only be embraced and not dismissed by being (to use the IIP term) "self-sacrificing." However, because the current study did not assess "If I . .., then they ..." expectations (e.g., Hill \& Safran, 1994), future research is needed to test the latter hypothesis.

To conclude, the good news is that people generally expected positive interactions. However, there were reliable individual differences in the types of interactions expected, and some of the differences were associ- 
ated with ongoing interpersonal problems. Uncommunal people expected others to be uncaring and uninterested, and in return expected themselves to be disconnected and unresponsive. Agentic people expected others to be critical, dismissive, and unsupportive, and in return expected themselves to be angry, rejecting, and argumentative. Communal people also worried that others might be dismissive, but expected themselves to react with shame rather than anger. Unagentic people did not expect more negative reactions from others, but did expect themselves to close down more when negative reactions did occur. The challenge for future research is to clarify why these associations exist and whether changing everyday interpersonal expectations can help people overcome enduring interpersonal problems.

\section{REFERENCES}

Alden, L. E., Wiggins, J. S., \& Pincus, A. L. (1990). Construction of circumplex scales for the Inventory of Interpersonal Problems. Journal of Personality Assessment, 55, 521-536.

Andersen, S.M., \& Chen, S. (2002). The relational self: An interpersonal social-cognitive theory. Psychological Review, 109, 619-645.

Asendorpf, J.B., Banse, R., \& Muecke, D. (2002). Double dissociation between implicit and explicit personality self-concept: The case of shy behavior. Journal of Personality and Social Psychology, 83, 380-393.

Baldwin, M.W. (1992). Relational schemas and the processing of social information. Psychological Bulletin, 112, 461-484.

Baldwin, M.W., \& Holmes, J.G. (1987). Salient private audiences and awareness of the self. Journal of Personality and Social Psychology, 53, 1087-1098.

Beck, A.T. (1976). Cognitive therapy and the emotional disorders. Oxford, UK, International Universities Press.

Bornstein, R.F. (1998). Implicit and self-attributed dependency strivings: Differential relationships to laboratory and field measures of help seeking. Journal of Personality and Social Psychology, 75, 778-787.

Bryk, A.S., \& Raudenbush, S.W. (1992). Hierarchical linear models: Applications and data analysis methods. Newbury Park, CA: Sage.

Carson, R.C. (1969). Interaction concepts of personality. Chicago: Aldine.

Cone, J.D. (1999). Introduction to the special section on self-monitoring: A major assessment method in clinical psychology. Psychological Assessment, 11, 411-414.

Dovidio, J.F., Kawakami, K., \& Gaertner, S.L. (2002). Implicit and explicit prejudice and interracial interaction. Journal of Personality and Social Psychology, 82, 62-68.

Fitzsimons, G.M., \& Bargh, J.A. (2003). Thinking of you: Nonconscious pursuit of interpersonal goals associated with relationship partners. Journal of Personality and Social Psychology, 84, 148-163.

Gable, S.L., Reis, H.T., \& Elliot, A.J. (2000). Behavioral activation and inhibition in everyday life. Journal of Personality and Social Psychology, 78, 1135-1149.

Gray, J. A. (1987). The psychology of fear and stress (2nd ed.). New York: Cambridge.

Gurtman, M. B. (1992). Construct validity of interpersonal personality measures: The interpersonal circumplex as a nomological net. Journal of Personality and Social Psychology, 63, 105-118. 
Gurtman, M. B. (1996). Interpersonal problems and the psychotherapy context: The construct validity of the Inventory of Interpersonal Problems. Psychological Assessment, $8,241-255$.

Higgins, E. T. (1998). Promotion and prevention: Regulatory focus as a motivational principle. In M. Zanna (Ed.), Advances in experimental social psychology (Vol. 30, pp. 1-46). San Diego, CA: Academic Press.

Hill, C.R., \& Safran, J.D. (1994). Assessing interpersonal schemas: Anticipated responses of significant others. Journal of Social and Clinical Psychology, 13, 366-379.

Honeycutt, J.M., \& Ford, S.G. (2001). Mental imagery and intrapersonal communication: A review of research on imagined interactions and current developments. In W.B. Gudykunst (Ed.), Communication yearbook 25 (pp. 315-345). Mahwah, NJ: Lawrence Erlbaum

Horowitz, L.M. (2004). Interpersonal foundations of psychopathology. Washington, DC: American Psychological Association.

Horowitz, L.M., Alden, L.E., Wiggins, J.S., \& Pincus, A.L. (2000). Inventory of Interpersonal Problems Manual. Odessa, FL: The Psychological Corporation.

Horowitz, L.M., Rosenberg, S.E., \& Bartholomew, K. (1993). Interpersonal problems, attachment styles, and outcome in brief dynamic psychotherapy. Journal of Consulting and Clinical Psychology, 61, 549-560.

Kenny, D.A., Kashy, D.A., \& Bolger, N. (1998). Data analysis in social psychology. In D.T. Gilbert, S.T. Fiske, \& G. Lindzey (Eds.), The handbook of social psychology (4th ed., pp. 233-265). New York: McGraw-Hill.

Kiesler, D.J. (1983). The 1982 interpersonal circle: A taxonomy for complementarity in human transactions. Psychological Review, 90, 185-214.

Locke, K.D. (2000). Circumplex Scales of Interpersonal Values: Reliability, validity, and applicability to interpersonal problems and personality disorders. Journal of Personality Assessment, 75, 249-267.

Matano, R., \& Locke, K.D. (1995). Personality disorder scales as predictors of interpersonal problems of alcoholics. Journal of Personality Disorders, 9, 62-67.

McClelland, D.C., Koestner, R., \& Weinberger, J. (1989). How do self-attributed and implicit motives differ? Psychological Review, 96, 690-702

Muran, J.C., Segal, Z.V., Samstag, L.W., \& Crawford, C.E. (1994). Patient pretreatment interpersonal problems and therapeutic alliance in short-term cognitive therapy. Journal of Consulting and Clinical Psychology, 62, 185-190.

Nezlek, J.B. (2001). Multilevel random coefficient analyses of event- and interval-contingent data in social and personality psychology research. Personality and Social Psychology Bulletin, 27, 771-785.

Osgood, C. E., Suci, G. J., \& Tannebaum, P. H. (1957). The measurement of meaning. Urbana, IL: University of Illinois Press.

Pierce, T., \& Lydon, J. (1998). Priming relational schemas: Effects of contextually activated and chronically accessible interpersonal expectations on responses to a stressful event. Journal of Personality and Social Psychology, 75, 1441-1448.

Pincus, A.L., \& Wiggins, J.S. (1990). Interpersonal problems and conceptions of personality disorders. Journal of Personality Disorders, 4, 342-352.

Reis, H.T., \& Gable, S.L. (2000). Event-sampling and other methods for studying everyday experience. In H.T. Reis \& C.M. Judd (Eds.), Handbook of research methods in social and personality psychology (pp. 190-222). New York: Cambridge University Press.

Soldz, S., Budman, S., Demby, A., \& Merry, J. (1993). Representation of personality disorders in a circumplex and five-factor space: Explorations with a clinical sample. Psychological Assessment, 5, 41-52.

Wagner, C.C., Kiesler, D.J., \& Schmidt, J.A. (1995). Assessing the interpersonal transaction 
cycle: Convergence of action and reaction interpersonal circumplex measures. Journal of Personality and Social Psychology, 69, 938-949.

Wheeler, L., \& Reis, H.T. (1991). Self-recording of everyday life events: Origins, types, and uses. Journal of Personality, 59, 339-354.

Wiggins, J. S., Trapnell, P., \& Phillips, N. (1988). Psychometric and geometric characteristics of the Revised Interpersonal Adjective Scales (IAS-R). Multivariate Behavioral Research, 23, 517-530.

Wilson, T.D., Lindsey, S., \& Schooler, T.Y. (2000). A model of dual attitudes. Psychological Review, 107, 101-126

Wood, J.V. (1996). What is social comparison and how should we study it? Personality and Social Psychology Bulletin, 22, 520-537. 
Copyright of Journal of Social \& Clinical Psychology is the property of Guilford Publications Inc.. The copyright in an individual article may be maintained by the author in certain cases. Content may not be copied or emailed to multiple sites or posted to a listserv without the copyright holder's express written permission. However, users may print, download, or email articles for individual use. 